\title{
Configurações
}

Revista de sociologia

\section{Experiências de acolhimento residencial e (re)construção identitária dos sujeitos acolhidos}

Residential care experiences and identity (re)construction of the welcomed subjects

Expériences d'accueil résidentiel et de (ré) construction identitaire des sujets.

\section{Paula Costa, Rui Santos and Ricardo Vieira}

\section{OpenEdition}

\section{Journals}

Electronic version

URL: http://journals.openedition.org/configuracoes/7321

DOI: 10.4000/configuracoes.7321

ISSN: $2182-7419$

\section{Publisher}

Centro de Investigação em Ciências Sociais

Printed version

Number of pages: 53-72

ISSN: 1646-5075

\section{Electronic reference}

Paula Costa, Rui Santos and Ricardo Vieira, « Experiências de acolhimento residencial e (re)construção identitária dos sujeitos acolhidos », Confiqurações [Online], 23 | 2019, Online since 28 June 2019, connection on 30 June 2019. URL : http://journals.openedition.org/configuracoes/7321 ; DOI : 10.4000/configuracoes.7321 
Costa, Paula; Santos, Rui; Vieira, Ricardo - Experiências de acolhimento residencial e (re)construção identitária dos sujeitos acolhidos. Configurações, vol. 23, 2019, pp. 53-72.

\title{
Experiências de acolhimento residencial e (re)construção identitária dos sujeitos acolhidos
}

\author{
PAULA COSTA* \\ Centro Social Paroquial Paulo VI \\ RUI SANTOS** \\ CICS.NOVA.IPLeiria \\ RICARDO VIEIRA*** \\ CICS.NOVA.IPLeiria
}

\section{Resumo}

Este artigo resulta de uma investigação etnobiográfica, cujo objetivo passa por compreender a perceção dos indivíduos adultos sobre a influência das experiências de acolhimento institucional na (re)construção da sua identidade. Foram feitos estudos de caso biográfico a 4 sujeitos que em algum momento da sua história de vida permaneceram em instituições de acolhimento residencial. Através da análise das entrevistas identificaram-se, nos sujeitos estudados, transformações identitárias, entre a infância e a adultez que vivem hoje, já no tempo pós-institucional. A pesquisa mostra que o acolhimento residencial permitiu aos entrevistados a aquisição de competências para se transformarem e idealizarem um futuro diferente do dos seus ascendentes.

Palavras-chave: Acolhimento residencial, crianças e jovens em risco, intervenção social, (re) construção identitária.

\footnotetext{
Abstract

Residential care experiences and identity (re)construction of the welcomed subjects This article presents the results of an ethnobiographic research, whose objective has been to understand the perception of adult individuals about the influence of residential care experiences on the (re)construction of their identity. Biographical case studies were done on 4 subjects, who at some point in their life history lived in residential care institutions. Through the analysis of the interviews were identified identity transformations

*E-mail: paula.costa_8@hotmail.com

**E-mail: rui.d.santos@ipleiria.pt

$* *$ E-mail: rvieira@ipleiria.pt
} 
that occurred within themselves, between the childhood and adulthood that currently live, already in the post-institutional time.

The research shows that the residential care allowed the interviewees to acquire the skills to transform themselves and to idealize a different future from their ascendants.

Keywords: Residential care, children and youth at risk, social intervention, identity (re) construction.

\section{Résumé}

Expériences d'accueil résidentiel et de (ré) construction identitaire des sujets.

Cet article est issu d'une étude ethnobiographique dont l'objectif est de comprendre la perception des individus adultes sur l'influence des expériences de réception institutionnelles sur la (re) construction de leur identité. Ces études de cas biographiques ont été réalisées avec 4 sujets qui à un moment de leur histoire de vie sont restés dans des institutions d' accueil. À travers l'analyse des entretiens, nous avons identifié les transformations identitaires qui se sont produites en eux-mêmes, entre l'enfance et l'âge adulte qui vivent aujourd'hui, déjà dans le temps post-institutionnel. La recherche montre que l' accueil institutionnel a permis aux personnes interrogées l' acquisition des compétences pour transformer et idéaliser un futur différent de leurs ancêtres.

Mots-clés: Résidentiel accueil, enfants et jeunes à risque, intervention sociale, (re) construction d'identité.

\section{Introdução}

Quando as famílias não apresentam competências para proteger, cuidar, defender e promover os interesses e direitos das crianças e jovens, estas ficam numa situação de vulnerabilidade, numa situação de carência, numa situação de risco. A existência de fatores de risco a curto, médio ou longo prazo, em função da gravidade que assumem, podem levar, direta ou indiretamente, consciente ou inconscientemente, a situações de maltrato. Os maus tratos podem ser caracterizados como todos e quaisquer atos ou omissões realizadas por indivíduos, instituições ou pela sociedade no seu conjunto e todas as situações derivadas destes atos que privem a criança da sua liberdade ou dos seus direitos e/ou que dificultem o seu ótimo desenvolvimento (Alberto, 1999; Alves, 2007; Canha, 2002; Leça et al., 2011).

Em Portugal estas situações são analisadas à luz da Lei de Proteção de Crianças e Jovens em Perigo (LPCJP) (aprovada pela Lei 147/99 de 1 de setembro de 2001, alterada em 2003 pela lei n. ${ }^{\circ}$ 31/2013, de 22 de agosto, e, em 2015 pela Lei n. ${ }^{\circ}$ 142/2015, de 8 de setembro), cuja finalidade é a promoção e proteção das crianças e jovens em perigo e o respetivo papel das entidades responsáveis na presente matéria. 
São as instâncias com poder em matéria de infância e juventude que aplicam medidas de promoção e proteção e que podem ser concretizadas em meio natural de vida ou em medidas de colocação (LPCJP, 2001, 2003, 2015).

Muitos têm sido os estudos que realçam os problemas da institucionalização de crianças e jovens (Alves, 2007; Calheiros, et al., 2013; Carvalho \& Cruz, 2015; Delgado, 2010; Santos, 2014). Por outro lado, também a opinião pública, construída e veiculada através dos meios de comunicação social, tem vindo a especular sobre a intervenção social e seus profissionais, sobre os processos de promoção e proteção e sobre as instituições de acolhimento de crianças e jovens em risco, nomeadamente, sobre o seu funcionamento e formas de educar. Neste estudo, a análise dos 4 sujeitos estudados, todos eles acolhidos institucionalmente por mais de 2 anos, mostra também as potencialidades e os sucessos da residencialização enquanto forma de institucionalização. ${ }^{1}$

De acordo com a legislação em vigor, a intervenção psicossocial, económica e, por vezes, judicial, é pautada por vários princípios, existindo, na nossa perspetiva, dois princípios basilares e fundamentais, o "interesse superior da criança e do jovem" e a "prevalência da família” (LPCJP, 2001, 2003, 2015). As medidas de colocação só são aplicadas quando as medidas em meio natural de vida não obtiveram resultado frutífero e não afastaram o perigo, logo, foram insuficientes para proteger a criança, existindo assim a necessidade de aplicar outras medidas. O acolhimento residencial perfila-se como uma das medidas de colocação mais utilizadas em Portugal. Este acolhimento "é um instrumento na retirada da criança da situação de perigo, protegendo-a, para, prevenindo novas exposições ao perigo, promover o seu desenvolvimento e a sua autonomia, com ela construindo o seu projeto de vida" (LPCJP, 2001, 2003, 2015).

Em Portugal, e de acordo com os últimos dados publicados pelo Instituto de Segurança Social (ISS) estiveram em situação de acolhimento residencial 10688 crianças e jovens no ano 2016. Destas, 2513 saíram do sistema de acolhimento no referido ano, 5779 iniciaram o acolhimento em anos anteriores e 2396 foram acolhidas no presente ano (CASA, 2017). No término de 2016, havia 8600 crianças e jovens acolhidos, situação que se mantém muito semelhante aos últimos 5 anos. Contudo, a mesma fonte ressalva que as crianças e jovens referenciados são apenas um universo exíguo no sistema de proteção, salvaguardando que as medidas de promoção e proteção em meio natural de vida, nomeadamente de apoio junto dos pais, são predominantes em detrimento das medidas de acolhimento. Desta forma, estariam a cumprir os princípios orientadores previstos na LPCJ, nomeadamente, a prevalência da

1 Face às representações sociais maioritariamente negativas da institucionalização, matéria bem sublinhada por Goffman no estudo das Instituições Totais (Goffman, 1961, 1963), as políticas sociais de acolhimento, materializadas recentemente na Lei 142/2015 de 8 setembro, passaram a usar o conceito de acolhimento residencial, aproximando-se, cremos, de um paradigma menos uniformizador e monolítico da institucionalização e mais próximo do trabalho individualizado com os sujeitos. 
família, a responsabilidade parental e o primado da continuidade das relações psicológicas profundas. Como dá conta Delgado (2001), não tem havido um investimento nas medidas de acolhimento familiar, continuando Portugal a ser um dos países europeus que mais institucionaliza.

Os sujeitos acolhidos no sistema de promoção e proteção têm, maioritariamente, idades compreendidas entre os 12 e os 20 anos, sendo que as instituições podem acolher jovens até aos 25 anos.

Relativamente às crianças e jovens em acolhimento residencial destaca-se a importância da planificação do projeto de vida de cada um, sendo que esse mesmo projeto deve ser desenvolvido desde a sua entrada até à saída da instituição.

O projeto de vida é um processo fundamental na intervenção social, transformação e educação dos sujeitos de uma forma autónoma e emancipatória (Velho, 1994). Sem projetos de vida, a intervenção social e a educação tornam-se processos de formatação, massificação e uniformização institucional para os sujeitos (Velho, 1994; Boutinet, 1992, 1997; Vieira, 2009). Nesta linha, a pedagogia do projeto tornou-se um instrumento fundamental nos processos de intervenção social que implicam uma transformação identitária dos sujeitos que têm de tomar a seu cargo o seu futuro com base no seu presente e ancoragem social no seu passado (Vieira, 2009). A legislação aludida a trás (LPCJP, 2001, 2003, 2015) vem, justamente, retomar o conceito de projeto de vida dos estudos biográficos e do desenvolvimento pessoal e social dos sujeitos na socialização, na ressocialização, na educação, na reeducação, ainda que num formato algo fechado. Efetivamente, de acordo a LPCJP, os projetos de vida passam pela reintegração familiar, autonomização e adoção. Estes podem, contudo, ser dinâmicos e ser alterados ao longo do acolhimento institucional, podendo iniciar-se com uma previsível reintegração familiar e, posteriormente, alterar-se para autonomização.

\section{Da (re)construção identitária e da intervenção social mediadora}

É através da análise das teorias de desenvolvimento que se percebe que a identidade do ser humano é desenvolvida ao longo da vida, na relação com o outro e entre os diferentes sistemas. A partir de vários autores percebemos que o conceito de identidade continua a ser difícil de definir pelo seu carácter subjetivo e mutante. Como refere Vieira "a identidade é um conceito vasto e extremamente complexo cuja definição não é, e, talvez, nuca será, linear, pois está sempre em manifesta construção, consoante as experiências que cada um de nós tem no mundo" (1999: 62). Assim, pode-se começar por referir que a identidade apresenta um caracter multi dinâmico e se encontra em constante transformação (Dubar, 1997, 2000; Lahire, 2002; Laplatine et Noouss, 2002; Maalouf, 1999; Velho, 1981, 1994; Vieira, 1999, 2009, 2011). Por outro lado, 
pode-se reafirmar que a mesma se desenvolve ao longo da vida, sendo defendido, no entanto, por diversos autores, (Erickson (1904 - 1994), Costa (1991)) que a adolescência é a fase crucial para a sua consolidação.

O sujeito desenvolve-se e cria a sua identidade através dos processos de socialização, sendo que, de acordo com Dubar (1997), estes são interativos e multidirecionais. Não transmitem apenas valores, normas e regras, nem são apenas resultados de aprendizagens formais, mas, antes, produto de uma construção lenta e gradual. A socialização não é mais que um processo de identificação e construção identitária de pertença e de relação com os outros. De acordo com Vieira (2011b: 47):

Para a identidade e cultura pessoal, concorrem não só a origem social e a socialização primária, onde se constrói a mente cultural do indivíduo (Iturra, 1990), mas também toda a trajetória biográfica que pode atravessar não só vários estratos sociais bem como várias mentalidades. O resultado, a identidade num dado momento, mista de individual e de coletivo (o individual, e mesmo o pessoal, o subjetivo, é também social) é pois, ainda um processo e não uma estrutura. É um terceiro instruido (Serres, 1993), uma terceira, quarta, quinta e mais dimensões de ser e estar, uma construção identitária, uma fusão entre o background já possuído e as alternativas culturais detetadas e interiorizadas pelo indivíduo.

Neste sentido, e tendo consciente o conteúdo do presente estudo, importa referenciar e analisar os conceitos de incidentes críticos, pessoas críticas e fases críticas desenvolvidos por Flanagan (1954), Sikes et al. (1985), Woods, (1993), Vieira $(1998,1999,2004)$ atendendo à forma como influenciam e promovem alterações internas nos sujeitos, alterações essas que estão na génese das reconstruções identitárias que vão ocorrendo ao longo da vida. Desde logo importa ressalvar que os conceitos referidos podem ocorrer de forma inconsciente ou consciente. Contudo, estes só se permitem ser analisados, refletidos, reconhecidos e identificados posteriormente, isto é, do presente para o passado (Vieira, 2011), numa análise retrospetiva com o distanciamento necessário, o que justifica a metodologia privilegiada de que falaremos adiante.

Assim, consideramos os incidentes críticos ou fases críticas como

momentos e episódios energéticos que têm enormes consequências para o desenvolvimento e mudanças pessoais. Não são planejados, antecipados ou controlados. São flashes que iluminam fortemente, em um momento, algum aspeto, ou aspetos problemáticos. (Woods, 1993: 1) 
Por outras palavras, são momentos da vida dos sujeitos, acontecimentos que ocorrem nas relações e interações com os outros, que, de alguma forma, são tão intensos, tão significativos, que agitam, fazem repensar e permitem a transformação do sujeito, possibilitando a sua reflexividade, levando à sua (re) construção, mesmo que de forma inconsciente. Só anos mais tarde, e com o trabalho relacional e de mediação intercultural, é possível identificar e compreender o que aquele acontecimento fez ao sujeito que o vivenciou, e como contribuiu para promover determinada mudança pessoal e identitária. $\mathrm{Na}$ mesma linha, as pessoas críticas são sujeitos que se cruzaram nas nossas vidas e que, por algum incidente, foram mais significativos e/ou tiveram um impacto maior em nós, positiva ou negativamente. É o que a psicologia chama de pessoas de referência (Bowlby, 1969). Vieira (1999; 2009) designa-os como terceiras pessoas na medida em que surgem aos sujeitos como modelos alternativos aos modos de fazer, pensar e olhar o quotidiano.

Assim, pode dizer-se que a construção identitária ocorre "através de um processo de metamorfose cultural, que, não raras vezes, coloca as pessoas numa encruzilhada reflexiva" (Vieira, 2011b: 61), e/ou numa ambivalência entre o self de ontem e o self de hoje. Neste sentido, Vieira (2009) identifica dois modelos possíveis da metamorfose cultural extremista: o oblato que representa as pessoas que rejeitam as suas origens socioculturais não fazendo a ligação entre o passado e o presente; e o trânsfuga intercultural que corresponde ao sujeito que "recebe o novo, mas não rejeita o velho. Incorpora no seu universo pessoal a aquisição cultural que dá uma dimensão à cultura de origem mas que não aniquila nem substitui. Antes sim, dá-lhe uma terceira dimensão, resultante da integração comparativa entre o nós e o ele.” (Vieira, 2011b: 66). Entre o self de ontem, o self de hoje e o self idealizado como projeto para amanhã.

Logo, a identidade dos sujeitos é, a todo o momento, contruída e (re)construída. Constitui-se como um terceiro instruído e, tal como refere Serres (1993), ilustra a "passagem de uma margem do rio para a outra" originando um novo ser, o "1 e 1=3" (Vieira, 1999, 2003, 2009, 2011). Neste contexto e de acordo com a bibliografia analisada (Dubar, 1997, 2000; Lahire, 2002; Laplatine et Noouss, 2002; Maalouf, 1999; Velho, 1981, 1994; Vieira, 1999, 2009, 2011) a identidade revela, em síntese, um carácter complexo, dialético, reflexivo, dinâmico, compósito, em que o todo é mais que as partes que a compõem, é intrínseca e única para cada indivíduo, é heterógena, mutável, mestiça e sempre em transformação. E é essa capacidade de transformação que permite acreditar na ressocialização, reeducação e na construção de projetos para crianças e jovens acolhidos residencialmente.

A (re)construção identitária dos acolhidos, e particularmente a dos quatro sujeitos estudados, corresponde também à possibilidade, ou não, de concretização desses dois modelos (Vieira, 2011b): (1) fazer tábua rasa do passado e idealizar um futuro totalmente diferente (oblato); (2) ou ligar reflexivamente as 
experiências individuais e sociofamiliares vivenciadas na infância e adolescência na perspetivação dum futuro construído como projeto de vida que assume a suas vivências e a sua história de vida como parte de um trajetória social com a qual constrói e projeta o seu futuro de uma forma idiossincrática (trânsfuga intercultural).

Surge aqui um papel fundamental para uma intervenção social mediadora (Vieira et Vieira, 2016) no sentido de construir pontes entre o self de ontem e o self de amanhã para que esse trabalho seja empoderador e autonomizador, deixando à criança/jovem alguma flexibilidade para gerir a dosagem das suas pertenças, quer aos contextos socioculturais de origem, ou de partida, quer ao presente, quer ao futuro projetado como ideal de vida. Isto implica uma transformação do self que passa por uma mediação intrapessoal potenciada pelo papel do interventor (Torremorrell, 2008).

\section{Metodologia}

Considerando que o objetivo desta investigação passa essencialmente por compreender a perceção dos indivíduos adultos sobre a influência das experiências de acolhimento institucional na (re)construção da sua identidade, a investigação tinha de, inevitavelmente, recorrer a paradigmas da complexidade (Morin, 2002) e a metodologias compreensivas (Amado, 2014; Faria et Vieira, 2016; Marques et al., 2016; Silva, 2009; Vieira, 2003, 2014), capazes de dar conta da transformação identitária dos quatro sujeitos estudados.

Assim, esta investigação recorre a retalhos de histórias de vida (O’Neill, 2003), de quatro sujeitos que entraram na instituição de acolhimento durante as suas infâncias e saíram entre os 17 e os 24 anos. As vozes destes sujeitos foram captadas com recurso a entrevistas inicialmente semi-estruturadas (Amado, 2014). Estas entrevistas tornaram-se em etnobiográficas (Vieira, 2003), na medida em que após a construção de um guião de entrevista que assinalava apenas o período anterior ao acolhimento, o período durante o acolhimento e o período pós-acolhimento, se passou a questionar o entrevistado a partir dos seus próprios relatos, buscando o seu aprofundamento autobiográfico. Neste sentido, privilegiou-se o estudo de caso biográfico uma vez que se analisam identidades pessoais e sociais, mais especificamente a (re)construção da identidade de 4 sujeitos acolhidos, "não como material histórico" (Amado, 2014: 169) mas, antes, como material para a reflexão e compreensão da transformação de si mesmo. Apesar das biografias aprofundarem o conhecimento do próprio sobre o seu passado e compreensão do presente, elas projetam também o futuro dos sujeitos estudados.

Os 4 sujeitos em estudo (cf. quadro 1) foram selecionados de acordo com os critérios estabelecidos previamente: que tivessem idade superior a 18 anos; que em algum momento da sua história tivessem vivido em acolhimento residencial 
ao abrigo da legislação (LPCJP, 2001, 2003, 2015); e que tivessem saído da referida instituição há pelo menos dois anos.

O quadro seguinte apresenta as características do universo de estudo ${ }^{2}$.

Quadro 1: Características dos sujeitos do estudo

\begin{tabular}{|l|c|c|c|c|}
\hline Identificação & S1 & S2 & S3 & S4 \\
\hline Sexo & Feminino & Feminino & 27 anos & Masculino \\
\hline Idade & 28 anos & 27 anos & $9^{\circ}$ ano \\
\hline $\begin{array}{l}\text { Escolaridade } \\
\text { Pós-Graduação } \\
\text { mento do aco- } \\
\text { lhimento }\end{array}$ & Freq. Universitária & $10 / 11$ anos & 5 anos \\
\hline $\begin{array}{l}\text { Tempo em } \\
\text { acolhimento }\end{array}$ & 19 anos & 12 anos & 7 anos & 13 anos \\
\hline $\begin{array}{l}\text { Idade na saída } \\
\text { acolhimento }\end{array}$ & 24 anos & 11 anos & 17 anos & 18 anos \\
\hline $\begin{array}{l}\text { Ano da saída } \\
\text { acolhimento }\end{array}$ & 2013 & 2011 anos & 2008 & 2010 \\
\hline
\end{tabular}

Fonte: Recolha do autor em trabalho de campo

Considerando os critérios apontados, o primeiro sujeito foi selecionado tendo em conta a proximidade social com o investigador, o que facilitou uma primeira aproximação a esta temática complexa. Um outro sujeito foi identificado no âmbito da prática profissional do investigador e de forma casuística. Os restantes membros foram surgindo com efeito bola de neve, indicados uns pelos outros (Carmo e Ferreira, 1998). O terceiro entrevistado foi sugerido pelo primeiro elemento e o último sujeito do universo de estudo foi sugerido pelo terceiro.

Neste processo, procurámos assegurar o direito à privacidade de cada participante, pelo que ao longo da presente investigação, estes são identificados como S1, S2, S3 e S4.

Outro procedimento adotado na investigação foi a elaboração do consentimento informado, sendo que o mesmo se traduziu numa autorização expressa dada pelo participante ao entrevistador, de forma escrita, depois de ter sido cuidadosamente esclarecido acerca dos objetivos da pesquisa. 
Todas as entrevistas foram realizadas em gabinete privado, de diferentes entidades públicas, de acesso restrito ao investigador, de forma a promover a confidencialidade dos participantes e assegurar que as entrevistas ocorressem em espaço neutro, confortável e sem interferência de terceiros. As entrevistas foram gravadas em registo áudio e duraram em média 100 minutos, devido ao facto destas serem de condução flexível, e os conteúdos abordados serem de cariz individual, complexo e emocionalmente exigentes para os participantes.

A técnica utilizada para o tratamento de dados e, de acordo com a natureza do estudo elencado, foi a análise de conteúdo qualitativa em consonância com a proposta de Guerra (2007: 78) que refere que "a análise categorial, que consiste na identificação das unidades pertinentes que influenciam determinado fenómeno em estudo "reduzindo o espaço de atributos» de forma a sacar apenas as variáveis explicativas pertinentes".

Em conformidade com os objetivos da presente investigação e em consonância com o trabalho de campo, foram identificadas três categorias de análise, nomeadamente, período anterior ao acolhimento, o período durante o acolhimento e o período pós acolhimento.

As referidas categorias foram desenvolvidas, analisadas e refletidas tendo em atenção a evolução do sujeito enquanto um ser biopsicosociocultural e de modo a melhor refletir a influência do acolhimento institucional na sua história de vida e na (re)construção identitária do seu self.

\section{Apresentação e discussão de resultados}

Os sujeitos identificados anteriormente foram acolhidos em três instituições residenciais. O S3 e o S4 estiveram na mesma instituição, no distrito de Leiria. O S1 e S2 estiveram em duas outras instituições diferentes, sendo uma do distrito de Leiria e outra do distrito de Santarém.

Desta investigação etnobiográfica, resultaram extensas narrativas, de enorme profundidade, que aqui se encontram resumidas a extratos dessas trajetórias de vida enquadradas nos três períodos em estudo, procurando fazer-se uma análise comparativa entre a reconstrução identitária dos quatro sujeitos estudados.

\subsection{Período anterior ao acolhimento}

Os sujeitos S1, S2 e S3 encontravam-se aos cuidados da família biológica antes do momento do acolhimento, conforme os próprios referem ao longo das entrevistas apresentadas:

"Vivia com os meus pais, os meus irmãos [...] sete irmãos" (S2) e "eu acho que era tipo a menininha dos papas [...] andava sempre com o meu pai para todo o lado [...] A minha mãe [...] tinha muito aquela coisa da proteção porque eu era a mais nova” (S1). 
S3 e o S4 estavam inseridos em agregados monoparentais. A este propósito $\mathrm{S} 3$ refere que

"[...] O meu pai já estava separado da minha mãe [...] o meu pai tinha se separado da minha mãe eu tinha 1 ano [...] sempre cresci com o meu pai”.

S4 sublinha que tinha completado 5 anos de idade quando foi acolhido, pelo que não se lembrava de viver com a família biológica. Contudo, refere que vivia com a mãe e é "filho de pai incógnito", pelo que até à data desconhece a identidade do pai.

A maioria dos elementos entrevistados recordam a vivência em família e a relação que estabeleciam com os cuidadores, excetuando-se o S4, que devido ao acolhimento precoce não se lembra de viver com a família.

Todos os sujeitos revelaram consciência dos principais motivos que os levaram ao acolhimento. Para S1 as principais problemáticas familiares passavam pela situação socioeconómica dos progenitores e as condições habitacionais. Por sua vez, S2 identifica o alcoolismo da progenitora como o principal motivo do acolhimento. No que concerne a S3 e S4, estes identificaram os problemas de saúde dos cuidadores como principal motivo conducente ao acolhimento.

Foram identificados incidentes críticos, pessoas críticas e fases criticas (Flanagan, 1954; Sikes et al. 1985; Vieira, 1998, 1999, 2004) relativamente a cada sujeito. Tendo em conta que todos os elementos foram acolhidos na fase da infância e que o período anterior ao acolhimento é relativamente curto, e dizemos relativamente porque mesmo que sejam 11 anos anteriores ao acolhimento só a partir dos $4 / 5$ anos de idade é que o nosso sistema começa a "armazenar" memórias, poucos foram os incidentes críticos / fases críticas e pessoas críticas identificadas com os sujeitos estudados.

Para o S1, a pessoa crítica, um modelo positivo neste caso, é o pai. Dele fala com emoção desculpando até alguns comportamentos que considera críticos:

"[...] efetivamente o meu pai [...] era um homem super inteligente [...], acho que, se calhar, não tomou as melhores opções de vida para estar na situação em que estava, mas sempre foi uma pessoa que apesar de tudo sempre tinha assim alguma sensatez [...]".

Relativamente a S2, o irmão mais velho, o pai e o vizinho são as figuras de referência, as pessoas críticas no sentido mais positivo para a idealização do seu projeto de vida. A mãe foi identificada como pessoa crítica pelo impacto negativo que teve na infância do elemento S2

"ela obrigou-me a ir [...] à GNR, e sentei-me no muro da GNR... [...] Sozinha [...] porque eu não queria entrar, né, eu não queria dizer 
- olha o meu pai bateu na minha mãe - e eu já lá tava, sei lá, para aí há 1 h e tal [...] e eu lembro-me que eles, um GNR veio cá fora [...] e foi ao pé de mim, e eu comecei a chorar, ele levou-me para dentro, deu-me um copo de água, e não sei quê, e teve ali a falar comigo, [...] e eu depois disse - o meu pai bateu na minha mãe, e eu disse-lhe - eu não queria, eu não queria vir aqui porque ela [...] também estava a picá-lo [...] eu depois não queria ir para casa porque tinha medo [...] ainda sou um bocadinho revoltada contra ela [...] (S2).

Sobre o S3 e S4 não conseguimos identificar pessoas críticas especificas em relação à infância.

O incidente crítico mais relevante na vida de todos os sujeitos entrevistados, apesar da diversidade das histórias de vida estudadas, é o momento da saída da família para integrar o acolhimento institucional. Assim, as palavras de S2 são bem ilustrativas a este propósito:

"Eu estava em casa, com os meus irmãos [...] eu ainda tentei fugir [...] e eu lembro-me que vinha, uma mulher polícia, um policia, e outra pessoa qualquer [...] que devia ser [...] sei lá uma assistente social, não sei. Porque en lembro-me que vinha uma mulher polícia porque en estava de pijama e ela foi connosco para o quarto, e ficou-nos a trancar a porta para nós mudarmos de roupa e nos vestirmos [...]."

Apesar deste período não ser o de memória mais viva nos relatos estudados, encontramos na saída um momento crítico e formador para os sujeitos que tudo fizeram para refazer a sua trajetória social e para se reinventarem (Flanagan, 1954; Sikes et al. 1985; Nóvoa e Finger, 1988; Boutinet, 1997; Josso, 2002; Kaufman, 2004; Vieira, 1999, 2009; Caride, 2016).

\subsection{Período do acolhimento}

No que concerne ao momento do acolhimento compreendemos que três dos acolhidos têm lembranças bem presentes do primeiro dia e da forma como foram rececionados na instituição. A narrativa de S3 é bem ilustrativa da importância desta memória:

"lembro-me, o primeiro dia, [...] embora aquilo fosse assim um bocado chocante ... no final do dia lembro-me que até não desgostei porque acima de tudo, qualquer miúdo com 10 ou 12 ou até mesmo 15, chega a um sítio com 50 ou 60 miúdos é pá, tipo, é brutal, e a gente nem sequer se lembra o que se está a passar na realidade [...]. Depois a educadora ... começou a mostrar-me a casa, a apresentar-me os miúdos, 
essa coisa toda, depois lembro-me que fui almoçar e depois à tarde, foi quando comecei a interagir com os miúdos [...]".

Assistimos aqui ao exemplo de um momento crítico do ponto de vista positivo que parece constituir a semente do sucesso da residencialização para o sujeito S3. Já no caso de S1 e S2, o momento do acolhimento constitui-se num momento de grande tensão e conflito. Ambos desconheciam o que iria acontecer. Só foram informados aquando integração na instituição pela técnica de acolhimento.

Refletindo sobre as suas dinâmicas e fatores institucionais, começamos por percecionar que as instituições identificadas continuam a revelar um espaço físico de grandes dimensões e acolhem entre 30 a 40 crianças, como os próprios referem:

"[...] à volta dos 40 [...] é a capacidade daquilo [...]” (S1), "[...] Era 30, 30 e poucos eu recordo-me [...]” (S2) "[...] houve várias oscilações 38, 42 [...]” (S4).

Este aspeto negativo do acolhimento distancia-se do ambiente individualizado, acolhedor e familiar (Alves, 2007; Pereira, 2013, Quintãns, 2013; Santos, 2010), mas, no entanto, e após análise das entrevistas, observa-se que os sujeitos não enfatizam essa questão, sublinhando, pelo contrário, que era um espaço como "a nossa casa” (S1), “chegava a casa” (S2), "ir a casa” (S3), "acabamos por ver essas pessoas como "mães" (S4). Assistimos ao poder transformador das crianças e jovens que conseguem nessa lógica do "1 e 1 =3" (Vieira, 1999), não só ser resilientes como também transformar os aparentes obstáculos em momentos de sucesso e de memórias de grande afeto.

Relativamente à partilha duma instituição com uma grande heterogeneidade etária, os sujeitos sublinham a mais valia de terem pares mais velhos para:

1) terem a quem recorrer para esclarecimento de dúvidas: "nós não vamos perguntar às miúdas da nossa idade porque nós não sabemos, vamos perguntar às mais velhas porque elas já sabem, já passaram por isso" (S1);

2) terem modelos a seguir ou, pelo contrário, a não seguir, ou seja, enquanto pessoas igualmente críticas (Woods, 1993): “por norma o pessoal mais velho naquela altura estava todo orientado..." [...] " quando havia confusões, quando havia alguém a andar à chapada, aparecia sempre um desses mais velhos... " (S3)

3) serem possíveis orientadores, mediadores de tensões e conflitos diversos: "esse pessoal é que metia a ordem, pronto se havia confusões, se havia, se alguém andasse à chapada, aparecia sempre um desses mais velhos” (S3).

No que respeita às questões escolares, S3 refere que o acompanhamento da instituição nesta matéria era exemplar: 
"[...]. Bastante, isso aí é uma daquelas coisas que por muito que um pai e uma mãe consiga, nunca consegue ter a mesma ligação que tem uma casa destas, pelo menos na altura quando foi da SS... Pronto, é o trabalho deles, estão ali um dia inteiro, só fazem aquilo, pronto, não escapava nada, nada [...]".

Conseguimos também perceber que a frequência escolar e a atenção ao estudo é considerada pelos sujeitos como tendo sido uma prioridade das instituições onde estiveram acolhidos. A este propósito, tanto S1 como S2 referem que se vivessem com os progenitores não conseguiriam estudar como nas casas de acolhimento. Estamos, uma vez mais, perante a capacidade que as crianças e os jovens têm em transformar episódios constrangedores, e mesmo estigmatizadores, em potenciais marcadores de uma identidade positiva. De novo o "1 e 1 = 3" (Vieira, 1999).

De igual modo, no que toca a cuidados de saúde gerais e específicos todos os elementos referiram serem sempre assegurados:

"havia sempre essa preocupação a questão de saúde, se estava bem e se não está bem e se precisa de alguma coisa, sempre houve muito esse acompanhamento, isso houve, por parte da ginecologia e tudo ... mesmo a questão das consultas de planeamento familiar e tudo” (S1).

Também aqui há um reconhecimento da importância da institucionalização no tocante ao acompanhamento de saúde, cuidados pessoais dos quatro biografados, cuidados que reconhecem que dificilmente teriam tido nas suas famílias.

Ainda relativamente às vantagens que os quatro sujeitos reconhecem ter usufruído vivendo em instituições de acolhimento, todos consideram as regras e rotinas como algo essencial à sua formação, sendo que as regras implementadas eram regras de respeito e convivência, bem como regras associadas às rotinas. As rotinas estavam associadas à planificação das atividades de satisfação das necessidades básicas (higiene, alimentação, etc.), de educação (estudo, trabalhos, etc.), bem como das atividades domésticas (arrumar o quarto, limpar a copa), sendo também estas atividades de índole formativo.

No seguimento da imposição de regras surgiam também castigos para quem não as cumprisse. S1 refere-se a estes como "medidas reparadoras" identificando-as usualmente como atribuição de duplicação das tarefas que já possuíam normalmente, consciência e reflexividade que se torna educadora e transformadora do self: 
"limpar as paredes [...] depois houve uma altura que era a parte da copa, do refeitório e da cozinha, supostamente a pessoa tinha que fazer tudo, à noite, depois do jantar, era o castigo” (S1).

Já S2 refere:

"Ó pá era do tipo coisas estúpidas, mas que tu ficavas danada né (risos) tipo ou não saias, ou ficavas sem ver televisão, ou ias para a cama mais cedo, ou, tipo imagina aquilo tinha horas de deitar diferentes".

No sentido de promover a autonomização dos jovens muitas vezes as competências básicas são transmitidas através das tarefas diárias

"[...] ter que ir para a costura [...] a questão da cozinha era uma questão que requeria algum cuidado, então eram sempre escolhidas as pessoas mais velhas da instituição para evitar não é, que aquilo não corresse bem [...] hoje em dia cozinho e cozinho bem, e gosto de cozinhar e há coisas que eu aprendi efetivamente de estar lá muitas vezes a ver, a aprender como é que se fazia [...]" (S1)

S2 referiu também que

"[...] tínhamos umas reuniões semanais [...] então depois elas falavam-nos das compras, e onde é que agente havia de comprar, e onde é que os congelados eram melhor [...] e ah depois tínhamos que fazer comer de vez em quando que era para aprender. [...] nós tínhamos $x$ dinheiro e nós tínhamos que nos orientar com aquele dinheiro pó mês todo [...].

Relativamente ao relacionamento com a família biológica ou de afeto (Santos, 2016) estas são referidas não tanto como fonte formadora de competências, assunto que remetem para a formação dentro da instituição, mas, essencialmente, como reguladores emocionais e afetivos, onde buscavam, nas visitas de fim de semana e de férias, o equilíbrio emocional e tranquilizador:

"[...] Tive um padrinho, uma pessoa que me acolhen [...] para eu poder lá passar os fins-de semana [...] era diferente, também tínhamos outras coisas, começamos a, a ganhar outros valores, valores a nivel pessoal [...] começamos a ganhar alguns hábitos também [...] Sim, uma família. Sim é bastante importante".

As pessoas de referências sublinhadas aquando da entrevista situam-se essencialmente no contexto da residencialização. Todos os elementos 
identificam uma pessoa de referência: uns, os auxiliares; outros a diretora técnica da casa; e outros as educadoras, que são vistas pelos entrevistados como fundamentais para o sucesso de uma situação de acolhimento:

"[...] a diretora, porque eu sempre tive uma relação, uma relação muito boa com ela, ainda hoje tenho e, e ela, ela falava muito comigo [...] porque ela foi... foi uma mãe para mim [...]” (S2).

Outra questão de grande relevância para que o acolhimento residencial seja uma resposta de promoção e proteção com sucesso prende-se com duas questões fundamentais: o projeto de vida e o processo de autonomização dos jovens.

No que concerne ao projeto de vida conseguimos perceber que o mesmo foi trabalhado ao longo dos anos em função das características da situação especifica de cada um. No caso de S1 a “[...] reintegração no seio familiar [...] , à medida que os tempos foram passando é que se tornou visível que essa situação não era possível. [...]”, configurando a emergência do oblato (Vieira, 1999; 2009; 2011; 2014), conceptualizado no ponto 2 , uma vez que há uma consciência da necessidade de cortar com o passado.

Quanto a S2, viveu na ambivalência entre sair ou permanecer na instituição. Acabou por sair apenas aos 21 anos, por opção, embora sempre mediada pela instituição que ajudou a encontrar o caminho no tempo certo. O projeto de vida passou pela autonomização, que foi preparada tendo em conta o superior interesse da jovem.

Os incidentes críticos/ fases criticas e pessoas críticas (Flanagan, 1954; Woods, 1993; Sikes et al., 1985; Vieira, 1998, 1999, 2004) são o momento do acolhimento residencial, são as estratégias de integração, o desenvolvimento de projeto de vida real e coeso e todo o processo de autonomização. As pessoas críticas são sem dúvida as pessoas de referência a nível institucional (educadoras, professores, diretores técnicos, etc.). No período de acolhimento residencial estas são as fases e pessoas que podem influenciar e promover alterações internas nos sujeitos, alterações essas que podem definir toda a sua trajetória de vida e que estão na génese das reconstruções identitárias e de projetos de vida futuros.

\subsection{Pós-acolhimento}

A saída do acolhimento é uma transição para uma vida mais autónoma e assume um carácter preponderante na emergência de um self autónomo. Tal saída pode ocorrer de modo previsível, transição normativa, ou inesperada e imprevisivelmente, transição não-normativa (Bronfenbrenner, 1996). Assim, S1 e S2 vivenciaram uma transição normativa progressiva, essencialmente por 
motivos escolares, tendo sempre na retaguarda o apoio da instituição; contrariamente para S3 e S4 a transição foi bastante diferente e mais inesperada. Com S3 foi uma decisão que o próprio tomou quando tinha 17 anos de idade:

[...] uma das coisas que me fez, fez desistir daquela casa foi mesmo isso [...] era não ter ninguém, ninguém com quem me identificasse, que me orientasse, ... fui ao gabinete da diretora, havia um papel para se preencher para sair da instituição... e eu preenchi o papel, às três pancadas e disse-lhe: olha en quero ir-me embora, vou arranjar trabalho $e$ depois vou para a tropa, pronto. [...].

Com S4 a transição resultou de uma ordem da própria instituição: “[...] eu acho que já tinha 19 na altura [...] Deram-me um prazo, disseram-me no dia $\mathrm{x}$ tens que sair [...]".

Atualmente, os quatro sujeitos encontram-se inseridos no mercado de trabalho, garantindo o seu próprio sustento e assegurando uma vida social autónoma. Dois deles têm filhos e todos eles vivem em "união de facto", tendo S2, S3 e S4 cortado o cordão umbilical com a família de origem [oblato] e tendo S1 reconfigurado as relações sociais com a família biológica [trânsfuga intercultural].

Os incidentes críticos / fases críticas no período pós-acolhimento são, para os quatro casos estudados, a transição para a saída da instituição e o acompanhamento pós-institucional.

Neste período de pós-acolhimento, nenhum dos casos identifica objetivamente a família biológica como pessoa crítica, nem no sentido positivo, nem no sentido negativo. As pessoas que efetivamente são reconhecidas como significativas [críticas positivamente] são aquelas que conheceram durante o período de acolhimento institucional [ex. técnicos, educadores] e no pós acolhimento [ex. amigos, namorados...].

Particularmente, S2 vive atualmente uma relação conjugal, da qual resultou o nascimento de um filho, e mantém laços fortes com a família biológica, que se envolve ativamente na educação do neto, configurando o modelo de trânsfuga intercultural, conceptualizado no ponto 2. Trata-se do modelo de sujeito que partiu da cultura de origem [família de origem] passando por projetos alternativos que, neste caso, passaram pela institucionalização, por um período de 11 anos, e que se autonomizou a partir da residencialização, conciliando hoje o projeto de vida a três [S2, esposo e filho] com a família de origem, reconhecendo que o passado fora resultado de circunstâncias sociais agora superadas e reconfiguradas. Efetivamente, a família de origem também se transformou e reeducou, abandonando o vício do álcool. Esta trajetória deixa de ser apenas 
pessoal para ser absolutamente social e promotora da transformação de si e dos outros.

\section{Em busca de conclusões}

As trajetórias de vidas estudadas, dos sujeitos S1, S2, S3 e S4, mostram-nos a existência de caminhos simultaneamente semelhantes e distintos como vimos. Todas revelam a existência de diversas problemáticas sociais, com maior enfase para as questões de carência económica, para a violência doméstica e para a ausência de competências parentais, no período de pré-acolhimento.

$\mathrm{O}$ acolhimento permitiu a estes jovens a aquisição de competências pessoais, sociais, económicas e profissionais, tendo conseguido a sua transformação e alcançando um futuro diferente dos ascendentes, tornando-se estes sujeitos trânsfugas interculturais no caso do sujeito S1 e oblatos no caso dos sujeitos S2, S3 e S4 (Vieira, 1999, 2009, 2014).

Foram identificadas pelos próprios sujeitos estudados pessoas e práticas institucionais que reconhecem como fundamentais para todo o processo da sua (re)construção identitária. No primeiro caso trata-se dos técnicos, das educadoras e outros sujeitos que foram referenciados como pessoas críticas, enquanto modelos positivos de comportamento. No segundo caso, as tarefas desempenhadas, quer no quotidiano da instituição, quer por castigo (por fuga a regra), são consideradas como transformadoras de si, promotoras de reflexividade e, portanto, de transformação e educação. As tarefas domésticas, nomeadamente, das limpezas gerais, do apoio à cozinha e o tratamento de roupas são um bom exemplo das competências adquiridas enquanto instituídos e também dos contributos para a autonomização do sujeito.

Também o acompanhamento escolar, o método, a disciplina e o controlo, como referem os sujeitos estudados, parecem ter sido fundamentais para a reconstrução identitária e a construção de projetos de vida autónomos.

Conclui-se que a existência de relações afetivas entre sujeitos e cuidadores/ técnicos das instituições são de extrema importância para o equilíbrio e estabilidade emocional dos sujeitos, como resulta da identificação que os sujeitos fazem das pessoas críticas positivas para a sua vida. Parece ser de extrema importância manter a ligação à "casa", manter a relação com os técnicos, mesmo após a saída do acolhimento. Essa ligação alimenta a identificação e a pertença a um lugar social e a alguém. Mesmo que de forma informal, este apoio pós acolhimento é fundamental para o sucesso da inserção social e laboral, bem como, para a estabilidade emocional.

Concluímos e observámos que a identidade de cada sujeito entrevistado é, em todo o momento, contruída e (re)construída, e, finalmente, origina a 
criação de um terceiro instruído (Serres, 1993), uma terceira pessoa, aquela que se autonomizou após a saída da residencialização.

Em suma, esta investigação mostra que um dos fatores chave potenciador de um acolhimento positivo parece passar por uma intervenção social mediadora, aquela que terá estado presente nas instituições que acolheram estes quatro sujeitos estudados, e que se concretizou numa intervenção capaz de compreender antes de agir, estudar antes de atuar, escutar ativamente antes de decidir e, finalmente, aquela que agiu, a partir de cada sujeito, em busca do seu próprio desenvolvimento, capacitação, empoderamento e autonomização.

\section{Referências bibliográficas}

AMADO, João (2014), Manual de Investigação Qualitativa em Educação, Coimbra, Imprensa da Universidade de Coimbra.

AZEVEDO, Joaquim (2007), “TCA: Trofa comunidade de aprendentes, um projeto de regulação sociocomunitária da educação”, In Xosé Cid \& Américo Peres (Eds.), Educação Social, Animação Sóciocultural e Desenvolvimento Comunitário (Vol. 2) (pp. 907-917), Vigo: Universidade de Vigo.

BAPTISTA, Isabel (2008), "Pedagogia Social: uma ciência, um saber profissional, uma filosofia de ação”, In Cárdenos de Pedagogia Social (pp. 7-30), Lisboa: Universidade Católica Portuguesa.

BOUTINET, Jean -Pierre (1992), Anthropologie du projet, Paris: PUF.

BOUTINET, Jean -Pierre (1997), “Métamorphoses de la vie adulte et incidences sue les méthodologies de la formation", in Education Permanente, Actualités des Pratiques (132).

BRONFENBRENNER, Urie (1979), The ecology of human development: Experiments by nature and design, Cambridge, Ma.: Havard University Press.

BRONFENBRENNER, Urie (1989), Ecological system theory, Annals of Child Development.

BRONFENBRENNER, Urie (1996), A Ecologia do Desenvolvimento Humano: Experimentos Naturais e Planejados, Porto Alegre: Artmed.

CARIDE, José (2016), "Lá Mediación como Pedagogía Social: Viejas Realidades, Nuevos Retos Para La Untervención Social”, In Ricardo Vieira, José Marques, Pedro Silva, Ana Vieira \& Cristóvão Margarido (Orgs.), Pedagogias de Mediação Intercultural e Intervenção Social (pp. 13-25), Porto: Edições Afrontamento.

CARMO, Hermano e FERREIRA, Manuela (1998), Metodologia da Investigação: Guia para a Autoaprendizagem, Lisboa: Universidade Aberta.

COSTA, Maria (1991), Contextos sociais de vida e desenvolvimento da identidade, Lisboa: Instituto Nacional de Investigação Científica.

DELGADO, Paulo (2009), Crianças e acolhedores. Histórias de vida em famílias, Porto: Profedições.

DUBAR, Claude (1997), A socialização. Construção das Identidades Sociais e Profissionais, Porto: Porto Editora.

DUBAR, Claude (2000), La crise des Identités. L'interprétation d'une Mutation, Paris: Presse Universitaires de France.

FLANAGAN, John (1954), "La technique de l'incident critique ", Revue Européenne de Psychologie Appliquée (vol. 4, n. 2) (pp. 165-185).

FREIRE, Paulo (2005), Pedagogia do Oprimido, Rio de Janeiro: Paz e Terra.

INSTITUTO DE SEGURANÇA SOCIAL (2017), CASA 2016 - Relatório de Caracterização Anual da Situação de Acolhimento das Crianças e Jovens, Instituto da Segurança Social, I.P.: Departamento de Desenvolvimento Social e Programas/ Unidade de Infância e Juventude. 
JOSSO, Marie Christine (2002), Experiências de Vida e Formação, Lisboa: EDUCA.

KAUFMANN, Jean-Claude (2004), L' Invention de Soi. Une Théorie de L'Identité, Paris: Armand Martin.

LAHIRE, Bernard (2002), O homem plural, São Paulo: Editora Vozes.

LAPLANTINE, François \& NOUSS, Alexis (2002), A mestiçagem, Lisboa: Piaget.

Lei n. ${ }^{\circ}$ 147/99, de 1 de setembro. Diário da República n. ${ }^{\circ}$ 204/99 - I Série A. Lisboa.

Lei n. ${ }^{\circ}$ 31/2003, de 22 de agosto. Diário da República n. ${ }^{\circ}$ 193/99 - I Série A. Lisboa.

Lei 142/2015, de 8 de setembro. Diário da República n. ${ }^{\circ}$ 175/15 - I Série A. Lisboa.

MAALOUF, Amin (1999), Identidades Assassinas, Lisboa: Difel.

NÓVOA, António \& FINGER, Mathias (1988), O Método Autobiográfico e a Formação, Lisboa: Ministério da Saúde.

O’NEILL, Brian (2003), "Histórias de vida de professores: a propósito do livro de Ricardo Vieira (Histórias de vida e identidades: Professores e Interculturalidade)", in Educação Sociedade \& Culturas (n. $\left.{ }^{\circ} 19\right)$ (pp 227-243).

PERES, Américo (2016), “Mediações Socioculturais: Conceitos e Contextos In Ricardo Vieira, José Marques, Pedro Silva, Ana Vieira \& Cristóvão Margarido (Orgs.), Pedagogias de Mediação Intercultural e Intervenção Social (pp. 57-72), Porto: Edições Afrontamento.

SIKES, Pat, MEASOR, Lynda, WOODS, James (1985), Teacher Carreers: crises and continuities, Lewes: Flamer Press.

SERRES, Michel (1993), O terceiro instruído, Lisboa: Piaget.

TORReMORREL, Maria (2008), Cultura de Mediação e Mudança Social, Porto: Porto Editora.

VELHO, Gilberto (1981), Individualismo e Cultura. Notas para uma antropologia da Sociedade Contemporânea, Rio de Janeiro: Zahar Editor.

VELHO, Gilberto (1994), Projecto e Metamorfose. Antropologia das Sociedades Complexas, Rio de Janeiro: Zahar Editor.

VIEIRA, Ana (2011), "Ensino Superior, mediação sociocultural e sociopedagógica”, A Página da Educação (193, II série), disponível em: http://www.apagina.pt/?aba=7\&cat=542\&doc= 14051\&mid=2 [consultado em 25 mar. 2016].

VIEIRA, Ana (2012), "Pedagogia Social nas escolas: um olhar sobre a mediação e educação social", Cadernos de Pedagogia Social (4), disponível em http://www.fep.porto.ucp.pt/sites/ default/files/files/FEP/CadernosPedagogiaSocial/CPSocial04.pdf [consultado em 15 maio 2016].

VIEIRA, Ana (2013), Educação Social e Mediação Sociocultural, Porto: Profedições.

VIEIRA, Ana. \& VIEIRA, Ricardo (2011), "Pedagogia Social, comunicação e mediação intercultural”, A Página da Educação (201, II série), disponível em http://www.apagina.pt/?aba $=7 \& \mathrm{cat}=561 \& \mathrm{doc}=14501 \& \mathrm{mid}=2$ [consultado em $25 \mathrm{mar}$. 2016]

VIEIRA, Ricardo (1998), "Etnografia e histórias de vida na compreensão do pensamento dos professores", In António Esteves \& José Azevedo (Eds.), Metodologias Qualitativas Para as Ciências Sociais (pp. 49-61), Porto: Universidade do Porto.

VIEIRA, Ricardo (1999), Histórias de Vida e Identidades: professores e interculturalidade, Porto: Afrontamento.

VIEIRA, Ricardo (2003), "Vidas revividas: a etnografia e a descoberta de novos sentidos", In Telmo Caria (Orgs.), Experiência Etnográfica em Ciências Sociais (pp. 77-96), Porto: Afrontamento.

VIEIRA, Ricardo (2004), E Agora Professor? A transformação na voz dos professores, Porto: Profedições.

VIEIRA, Ricardo (2009), Identidades Pessoais - interações, campos de possibilidade e metamorfoses culturais, Lisboa: Edições Colibri. 
VIEIRA, Ricardo (2014), “Trajetórias de vida, subjetivação e qualidade de vida de idosos”, In: José Luís Almeida, Paula Sousa, \& Hélder Afonso (Org.), Perspetivas sobre o envelhecimento ativo (pp. 145-162). Lisboa, Editorial Cáritas.

VIEIRA, Ricardo (2014), Life Stories, Cultural Métissage and Personal Identities, disponível em; http://sgo.sagepub.com/content/4/1/2158244013517241 [consultado em 25 jun. 2014].

VIEIRA, Ricardo (s/d), A construção do homem: identidades e metamorfoses, disponível em https://iconline.ipleiria.pt/bitstream/10400.8/274/1/n2_art2.pdf [consultado em 15 jan. 2015].

VIEIRA, Ricardo \& VIEIRA, Ana (2016), “Mediações Socioculturais: Conceitos e Contextos”, In Ricardo Vieira, José Marques, Pedro Silva, Ana Vieira \& Cristóvão Margarido (Orgs.), Pedagogias de Mediação Intercultural e Intervenção Social (pp. 27-56), Porto: Edições Afrontamento.

WOODS, Peter (1993), Critical events in teaching and learning, Londres: The Falmer Press. 